ПІНЕВИЧ Т. О., старший викладач (Державний університет інфраструктури та технологій, Київський інститут залізничного транспорту)

\title{
Стандартизація інфокомунікаційних мереж та систем
}

Однією із основних проблем при створенні Глобальної інформаційної інфраструктури (ГІІ) є вирішення сумісності національних систем і мереж. Тому нормативне правове забезпечення побудови та експлуатації інфокомунікацій з огляду на глобальний характер має здійснюватися не тільки на національному, а й на міжнародному рівнях. Вирішенням цієї проблеми займається ряд міжнародних організацій $i$ форумів, які розробляють стандарти і специфікащії в галузі інфокомунікацій. У роботі наведено основні характеристики та результати діяльності організацій зі стандартизації інфокомунікачійних мереж $і$ систем та відмічено, щзо важливою національною програмою є створення високоефективних телекомунікаційних систем $i$ мереж Украӥни на базі єдиних європейських та міжнародних стандартів і специфікацій у галузі інфокомунікацій.

Ключові слова: глобальна інформаційна інфраструктура, інфокомунікацї, стандарт, специфікація, протокол, стек протоколів, NGN, еталонна модель взаємодії відкритих систем.

\section{Вступ}

Технологічною основою інформаційного суспільства є Глобальна інформаційна інфраструктура (Global Information Infrastructure, GII), яка повинна забезпечити можливість доступу до інформаційних ресурсів кожного користувача планети [1-3].

Доступ до інформаційних ресурсів ГІІ реалізується за допомогою послуг зв'язку нового типу, які отримали назву послуг Інформаційного суспільства або інфокомунікаційних послуг, що здійснюють автоматизовану обробку, зберігання або надання інформації за запитом 3 використанням засобів обчислювальної техніки як на вхідному, так i на вихідному кінці з'єднання [4].

Розвиток інформаційно-комунікаційних послуг потребує вирішення завдань ефективного управління інформаційними ресурсами 3 одночасним розширенням функціональності мереж зв'язку та спрямовує їх розвиток на основі єдиної технічної політики відповідно до міжнародних стандартів.

\section{Аналіз останніх досліджень та публікацій \\ Проаналізувавши основні концепції розвитку, конкретні плани та реалізацію інфокомунікаційних мереж наступного покоління (NGN) зарубіжних та вітчизняних операторів, необхідно зазначити важливість вирішення питань зі стандартизації обладнання та протоколів взаємодії систем, а також взаємодію постачальників i користувачів, які отримують значні вигоди при застосуванні відкритих систем і мереж $[4,5]$.}

(C) Т. О. Піневич, 2018
Інфокомунікаційні системи (ІКС) мають у своєму складі різноманітне устаткування, тому в цих умовах проблема сумісності стає найбільш суттєвою. Через це стандартизація мережевих протоколів $€$ одним 3 найважливіших напрямків у галузі зв'язку. 3 огляду на глобальний характер сучасних інфокомунікацій правове забезпечення завдань їх побудови та експлуатації повинно здійснюватися не тільки на національному, а й на міжнародному рівнях [6].

Відкритий характер стандартів та специфікацій важливий як для мережевих протоколів i всіх пристроїв, так і для програм, створених для побудови мережі. Тому на цей час більшість стандартів $\epsilon$ відкритими.

Незаперечними перевагами дотримання принципів відкритості є:

- можливість побудови системи (мережі) 3 апаратних і програмних засобів різних виробників, які дотримуються одного і того ж стандарту;

- зменшення витрат на розроблення мережевого програмного забезпечення;

- заміна окремих компонентів мережі іншими більш досконалими, що дає змогу мережі розвиватися 3 мінімальними витратами;

- легкість сполучення однієї мережі 3 іншою, а також об'єднання на одному рівні центрів (пристроїв) управління різних мереж;

- прийняття ефективних взаємопов'язаних мережевих рішень, які забезпечують економію витрат і надають більші можливості обміну даними;

- створення конкурентоспроможного світового ринку виробів і продуктів.

Розвиток галузі зрештою відображено саме в стандартах, так як будь-яка нова технологія тільки тоді набуває законного статусу, коли їі зміст закріплюється відповідним стандартом [1 - 3]. 
Визначення мети та завдання дослідження

Навести основні характеристики європейських та міжнародних організацій зі стандартизації: Міжнародного союзу електрозв'язку (ITU International Telecommunication Union), Свропейського інституту зі стандартизації телекомунікацій (ETSI European Telecom-munications Standards Institute), Міжнародної організації стандартизації (ISO International Organization for Standardization) та ін.

Висвітлити результати іх діяльності, пов'язані 3 розробленням рекомендацій, стандартів та інших документів, які регулюють галузь i забезпечують можливість взаємодії і взаємозв'язок між великою різноманітністю додатків і різних платформ на основі програмних та апаратних засобів.

\section{Основна частина дослідження}

Актуальність питань
стандартизації інфокомунікаційних мереж і систем $є$ основним у розвитку Глобальної інформаційної інфраструктурі.

Концепції Next Generation Networks (NGN), на базі якої розвиваються і створюються універсальні мережі, утворюються на основі еталонної моделі взаємодії відкритих систем (ЕМВВС) [4].

ЕМВВС $є$ концептуальною основою, що визначає характеристики і засоби відкритих систем та забезпечує роботу в одній мережі систем, що випускають різні виробники, у тому числі:

- взаємодію прикладних процесів;

- форми подання даних;

- однакове зберігання даних;

- управління мережевими ресурсами;

- безпеку даних і захист інформації;

- діагностику програм і апаратних засобів.

Реалізація відкритих систем забезпечується сукупністю стандартів, за допомогою яких уніфікується взаємодія апаратних засобів і всіх компонентів програмного середовища (мов програмування, систем управління базами даних, засобів введення-виведення, графічних інтерфейсів, мережевих протоколів та ін.)

Стандарти як нормативно-технічні документи, що встановлюють вимоги до засобів зв'язку (автоматизаціï) i процесу передачі повідомлень, як правило, основані на консенсусі, тобто угоді зацікавлених сторін. Добровільність відрізняє стандарт від правових норм, які мають обов'язковий характер. Консенсус добровільних норм досягається в рамках визнаної структури (організації зі стандартизаціі). Базовий стандарт - це розроблений Державний стандарт, Міжнародний стандарт (наприклад, ISO / IEC), Технічний звіт або Рекомендація MCE-T.

Специфікація - це формалізований опис апаратних або програмних компонентів, способів їх функціонування, взаємодії з іншими компонентами, умов експлуатації та особливих характеристик.
Відкрита специфікація - загальнодоступна специфікація, яка підтримується відкритим професійним погоджувальним процесом, спрямованим на постійну адаптацію нової технології, та відповідає стандартам. Відкрита специфікація не залежить від конкретної технології та однаково доступна кожній зацікавленій стороні.

На основі базових стандартів формуються профілі протоколів, які $\epsilon$ взаємопов'язаною упорядкованою сукупністю базових стандартів, що орієнтовані на виконання конкретної прикладної функції та на побудову конкретної системи. Основу профілю становить спеціалізований набір (комбінація) OSIсумісних протоколів, що утворюють узгоджений стек, який не залежить від різних виробників мережевого обладнання.

Таким чином, стандарти і специфікації містять погодження, досягнуті відповідними організаціями зі стандартизації в певній галузі.

Міжнародний союз електрозв'язку (MCE, ITU International Telecommunication Union) - одна 3 найстаріших міжнародних організацій, заснована в 1865 році в Парижі, до складу якої входили Міжнародний консультативний комітет 3 телеграфії i телефонії (МККТТ) та міжнародний консультативний комітет 3 радіо та телебачення (МККРТ), які розробляли серії рекомендацій і стандартів, а з березня 1993 року був створений сектор зі стандартизації Міжнародного союзу електрозв' язку (MCE-T, ITU-T).

Основним напрямком діяльності MCE $\epsilon$ розроблення рекомендацій, які охоплюють практично всю галузь телекомунікацій і покликані забезпечити взаємодію телекомунікаційних мереж різних країн.

Рекомендації являють собою керівні матеріали і на відміну від стандартів не містять вимог, проте, переважна більшість країн на практиці розглядає рекомендації МСЕ як діючі стандарти. Стандарти МСЕ не $\epsilon$ обов'язковими, але підтримуються більшістю учасників телекомунікаційного ринку.

Сьогодні МСЕ - це міжнародний глобальний форум під егідою Організації Об'єднаних Націй $(\mathrm{OOH})$, який має у своєму складі більше ніж 190 країнучасниць, понад 550 членів секторів (бізнес, міжнародні та міжурядові організації), відкритий процес підготовки i прийняття рекомендацій, прийняття рішень на основі консенсусу, безкоштовний доступ до затверджених рекомендацій (у тому числі на сайті www.itu.int в мережі Інтернет).

Після ряду структурних змін основні робочі органи МСЕ подані трьома секторами:

- стандартизації електрозв'язку (ITU-T), який виконує міжнародну координацію в галузі стандартизації всіх телекомунікацій і 3 цією метою випускає різноманітні рекомендації;

- радіозв'язку (ITU-R), що відповідає за розподіл радіочастот; 
І Н Ф О Р М А Ц Й Н О - КЕ Р У Ю Ч І С И С Т Е МИ Н А З А Л І З Н И Ч Н О М У Т Р А Н С П О Р Т І

- розвитку електрозв'язку (ITU-D), що виконує обов'язки MCE, пов'язані з проектами розвитку в галузі телекомунікацій та управління фінансуванням об'єднаних проектів у розвинених країнах.

У кожному 3 трьох секторів утворений ряд дослідницьких комісій (IК або SG (Study Group), кожна з яких має свій порядковий номер і виконує свої обов'язки.

Окрім того, створено Спеціальну дослідницьку комісію (SSG - Special Study Group), яка вивчає мережеві аспекти систем мобільного зв'язку третього покоління IMT-2000 і наступних систем.

Для зручності роботи ІК можуть ділитися на кілька робочих груп (підкомісій), що включають експертів країн-учасниць. У свою чергу ці робочі групи, за необхідності, розбиваються на підгрупи, у яких ведеться основна діяльність, пов'язана з розробленням рекомендацій та інших документів МСЕ. Кількість і склад комісій (підкомісій) постійно змінюється 3 урахуванням сучасних пріоритетів у галузі стандартизації.

Для прискорення стандартизації мереж наступного покоління (NGN) за основними напрямками (послуги, функціональна архітектура, міжмережева взаємодія, еволюція мереж, комутація) створені робочі групи (WG - Work Group), у яких беруть участь представники всіх ІК. У ролі координатора всіх робіт у 2004-2005 роках виступала Центральна група по NGN (FG-NGN - Focus Group on NGN), пізніше для цього утворена Всесвітня ініціатива зі стандартизації NGN (NGN-GSI-NGN Global Standardization Initiative).

MCE працює в тісному контакті з низкою інших міжнародних, європейських, американських i азіатських організацій, прямо або побічно залучених у роботи, які стосуються стандартизації в галузі зв'язку.

Європейський інститут зі стандартизації телекомунікацій (ETSI - European Telecommunications Standards Institute) був утворений у 1988 році як незалежна некомерційна організація, на яку офіційно покладено завдання зі стандартизації європейських інформаційних і телекомунікаційних систем. Стандарти, які розробляються, покликані забезпечити сумісність національних систем електрозв'язку, що $є$ однією $з$ умов ефективності інтеграційних процесів у Європі. Європейським інститутом зі стандартизації телекомунікацій були успішно стандартизовані система стільникового зв'язку GSM i система професійного мобільного радіозв'язку TETRA.

Формально стандарти ETSI обов'язкові тільки для європейських країн. Незважаючи на це, ряд організацій, які розташовані за межами Свропи, також стали членами ETSI. Сьогодні в ETSI входить понад 700 членів від 59 країн Свропи i ряду інших континентів. Цей факт зумовлений низкою причин, серед яких слід відмітити ефективність роботи ETSI і важливий внесок Європи у розвиток міжнародних інфокомунікацій. Серед членів інституту більш ніж половина - це виробники обладнання, оператори зв'язку, провайдери послуг, дослідницькі центри. Цим ETSI відрізняється від МCE, у якому домінують адміністрації зв'язку країн, які безпосередньо входять до його складу [5].

Основну роботу ETSI в галузі стандартизації виконують технічні комітети (Technical Committees). Ïx перелік наведено на сайті www.etsi.org. На цьому ж сайті можна знайти докладну інформацію, що стосується організаційних і технічних аспектів роботи ETSI.

Комітети ETSI розробляють ряд проектів (ETSI Projects). Найбільш відомими 3 них $є$ : Проект TIPHON (Telecommunications and Internet Protocol Harmonization Over Networks) 3 розвитку IP-телефонії, Проект TISPAN (Telecoms and Internet converged Services and Protocol for Advanced Networks) 3 дослідження різних аспектів NGN, Проект UMTS (Universal Mobile Telecommunications System) зі створення систем зв'язку 3 рухомими об'єктами четвертого покоління, Проект BRAN (Broadband Radio Access Networks) 3 реалізації широкосмугових мереж абонентського радіодоступу.

Технічні рішення 3 найважливіших питань розвитку електрозв'язку приймаються і в ETSI, і в ITU після взаємних консультацій. Вони результативно співпрацюють і координують свої роботи з багатьма іншими організаціями. Основними з них є:

- Міжнародна організація стандартизації (ISO International Organization for Standardization) є автором стандартів у різних галузях діяльності, зокрема стандартів $з$ телекомунікацій. Членами ISO (MOC) $\varepsilon$ національні організації стандартизації. Участь в ISO $\epsilon$ добровільною. Найбільш відомим стандартом МОС у галузі телекомунікацій є EMBBC (ISO/ OSI);

- Міжнародна електротехнічна комісія (IEC International Electronical Committe). Основну увагу IEC (MEК) приділяе таким питанням, як електровимірювання, тестування, утилізація, безпека електротехнічного й електронного обладнання. Членами IEC $\epsilon$ національні організації (комітети) стандартизації технологій у відповідних галузях, що представляють інтереси своїх держав у справі міжнародної стандартизації;

- Інститут інженерів 3 електротехніки та електроніки (IEEE - Institute of Electrical and Electronics Engineers) - професійна організація, яка розробляє стандарти для мереж. Стандарти локальних мереж (LAN) $є$ найбільш відомими стандартами IEEE 3 телекомунікацій;

- Європейська конференція адміністрацій пошт i електрозв'язку (СЕРT - Conference of European Posts and Telegraphs);

- Європейська асоціація виробників обчислювальної техніки (ЕСMA - European Computer Manufactures Association); 
І Н Ф О Р М А Ц Й Н О - КЕ Р У Ю Ч І С И С Т Е МИ Н А З А Л І З Н И Ч Н О М У Т Р А Н С П О Р Т І

- Рада 3 регулювання роботи Інтернет (ІАВ Internet Activities Board) визначає основну політику в галузі глобальної мережі Інтернет. Складається з двох підкомітетів: дослідницького - IRTF (Internet Reseach Task Forse) і стандартизації - IETF (Internet Engineering Task Forse). Стандарти IAB називаються RFC (Request for Comments - запит для коментарю);

- Американський національний інститут стандартизації (ANSI - American National Standard Institute) $\epsilon$ координуючим органом добровільних груп зі стандартизації в межах США. ANSI $є$ членом ISO. Найбільш відомим стандартом ANSI 3 комунікацій $є$ FDDI. Найбільш відомими групами ANSI є: Асоціація електронної промисловості (EIA - Electronic Industrial Association) i Асоціація телекоммунікаційної промисловості (TIA - Telecommunication Industrial Association). Остання 3 них випускає стандарти 3 телекомунікацій, найвідомішим 3 яких $\epsilon$ стандарт стільникової системи радіозв'язку США - IS-54.

Зазначені організації активно співпрацюють у галузі стандартизації з безліччю консорціумів (Forum), створених виробниками мережевого обладнання, що зацікавлені у швидкому впровадженні конкретної технології.

Це такі організації, як GSM Forum, MSF Forum (Multiservice Switching Forum), MPLS Forum (Multiprotocol Label Switching Forum), MEF Forum (Metro Ethernet Forum), Forum Gigabit Ethernet, SIP Forum (Session Initiation Protocol Forum), BCD Forum (Broadband Content Delivery Forum) та ін.

А також міжнародні партнерські групи 3GPP i 3GPP2, організовані за безпосередньої участі ITU i ETSI, які зробили внесок у стандартизацію інфокомунікаційних систем (IКC) наступного покоління.

Партнерство 3GPP (3rd Generation Partnership Project) створене у 1998 році з ініціативи ETSI для розроблення технічних специфікацій і стандартів для мобільних мереж зв'язку 3G (мереж UMTS), які базуються на мережах GSM, що розвиваються. До складу 3GPP, крім ETSI, увійшло кілька національних організацій зі стандартизаціi: ARIB - Association of Radio Industries and Businesses (Японія), CCSA - China Communications Standards Association (Китай), ATIS Association for Telecommunications Industry Solutions (Північна Америка ), ТTА - Telecommunications Technology Association (Корея), ТTC Telecommunications Technology Committee (Японія).

Партнерство 3GPP2 з'явилося в тому ж році також 3 ініціативи ETSI і ITU для розроблення стандартів мобільних мереж зв'язку 3G (мережі CDMA2000) у рамках проекту IMT-2000, створеного під егідою ITUТ. Це партнерство було утворено практично тими ж організаціями, що і 3GPP - ARIB, CCSA, TTA, TTC i TIA $[5,6]$.

У цілому стандарти мереж мобільного зв'язку розробляються, орієнтуючись на широке застосування IP-орієнтованих протоколів, що стандартизовані ITU i IETF і застосовують основні ідеї архітектури NGN.

Ряд галузей опосередковано впливають на мережеві стандари. Істотний вплив мають один на одного обчислювальна техніка, інформатика і зв'язок. Завдяки такому взаємному впливу з'явився новий термін - інфокомунікації, який гармонічно об'єднав ці галузі.

Залежно від статусу організацій, що ведуть роботи зі стандартизації, розрізняють такі види стандартів:

- стандарти окремих фірм (наприклад, стек протоколів SNA компанії IBM або графічний інтерфейс OPEN LOOK для Unix- систем компанії Sun);

- стандарти спеціальних комітетів і об'єднань (форумів), створені декількома компаніями, наприклад, стандарти технології АТМ розробляє спеціально створене об'єднання АТM Forum, яке нараховує близько 100 колективних учасників, або стандарти союзу Fast Ethernet Alliance 3 розроблення стандартів Ethernet;

- національні стандарти, наприклад, стандарт FDDI, що представляє один з численних стандартів інституту ANSI, або стандарти безпеки для OC, розроблені центром NCSC Міністерства оборони США;

- міжнародні стандарти, наприклад, еталонна модель OSI і стек комунікаційних протоколів ISO, численні стандарти ITU, у тому числі стандарти на мережі X.25, FR, ISDN, модеми та багато ін. [6, 7].

У результаті співпраці багатьох національних i міжнародних організацій визначено набір стандартів, що враховують різні аспекти відкритих систем. Ряд стандартів були об'єднані в так звані стеки мережевих протоколів, які широко застосовуються для побудови мереж зв'язку різних за масштабом і призначенням. Основна увага при цьому приділена протоколам стека TCP / IP, переваги якого дали змогу впроваджувати їх для всіх типів мереж. Стек протоколів ТСР / IP удосконалюється (наприклад IPv6) 3 метою підтримки додатків голосу, відео, мультимедіа підвищеної якості. Особливе місце в стеку посідають протоколи SNMP (Simple Network Management Protocol) i RMON (Remote Monitoring), за допомогою яких відстежують стан мережі і проводять іiі адміністрування.

Отже, без узгодження всіма учасниками телекомунікаційного ринку (операторами, виробниками та постачальниками обладнання, користувачами) загальноприйнятих стандартів для обладнання і протоколів, прогрес у справі побудови інфокомунікаційних мереж був би неможливий.

У нашій країні національний оператор електрозв'язку ПАТ «Укртелеком», який $\epsilon$ найпотужнішим постачальником телекомунікаційних послуг в Україні, ефективно співпрацює $з$ провідними 
операторами розвинутих країн світу та бере участь у діяльності світових організацій зв'язку та інших глобальних і регіональних міжнародних організацій.

Міжнародні організації, 3 якими співпрацює Укртелеком [8]:

1. Міжнародний союз електрозв язку (MCE).

2. Регіональна співдружність в галузі електрозв'язку (РС3).

3. Європейський банк реконструкції та розвитку (СБРР).

4. HATO.

5. Міжнародні організації супутникового та космічного зв`язку (MO CKC): EUTELSAT, MOK3 Інтерсупутник, INTELSAT [9].

6. Свропейська конференція адміністрацій зв`язку (СЕПТ).

7. Свропейський Союз (СС).

Одним 3 пріоритетів ПАТ «Укртелеком» $\epsilon$ співпраця 3 міжнародними організаціями, що зумовлює розвиток зовнішньоекономічних зв'язків у галузі телекомунікацій за нижченаведеними напрямами:

1. Приєднання до міжнародних та європейських телекомунікаційних союзів, комісій, комітетів та об'єднань, а також участь у міжнародних конференціях, семінарах, виставках, які проводяться під егідою зазначених організацій.

2. Послідовне впровадження міжнародних стандартів на основі вивчення рекомендацій міждержавних структур (ITU, ETSI, PC3 та ін.) у галузі телекомунікацій $[10,11]$.

3. Залучення іноземних кредитів та інвестицій 3 метою розвитку мереж і послуг ПАТ «Укртелеком».

\footnotetext{
Висновки

Згідно 3 міжнародними деклараціями, які стосуються побудови інформаційного суспільства, перед Україною постає важливе завдання прискорити темпи розвитку національної інформаційної інфраструктури, узгодженої за принципами й поєднаної 3 Глобальною інформаційною інфраструктурою. Тому відповідно до положень Закону України «Про Концепцію національної інформаційної політики» до основних вимог щодо національної інформаційної інфраструктури належать такі:

- створення єдиної національної інтегрованої мультисервісної широкосмугової мережі зв'язку, до складу якої входять загальнодержавні та відомчі мережі, однією з яких $є$ мережа зв'язку Укрзалізниці [12];

- створення і впровадження вітчизняних безпечних інформаційних технологій із забезпеченням необхідного рівня якості функціонування та систем захисту інформації від несанкціонованого доступу та несанкціонованого поширення.
}

На сьогодні рівень розвитку технологічних розробок, виробництва та впровадження в різні сфери діяльності інфокомунікаційних систем багато в чому формує позитивний образ передової держави.

\section{Список використаних джерел}

1. Recommendation ITU-T Y.100. General overview of the Global Information Infrastructure standards development [Electronic resource]. - Access mode : https://www.itu.int/rec/T-REC-Y.100-199806-I/en (дата звернення 10.10.2018).

2. Recommendation ITU-T Y.110. Global Information Infrastructure principles and framework architecture [Electronic resource]. - Access mode : https://www.itu.int/rec/T-REC-Y/e (дата звернення 25.09.2018).

3. ITU-T Recommendation Y.2201.NGN release 1 requirements / International Telecommunication Union - Telecommunication Standardization Sector. 2009. - [Electronic resource]. - Access mode: https://www.itu.int/ITU-

$\underline{\text { T/recommendations/rec } . \text { aspx } \text { ?rec }=9879 \& \text { lang=en }}$ (дата звернення 25.09.2018).

4. Крук, Б. И. Телекоммуникационные системы и сети [Текст]: учеб. пособие / Б. И. Крук, В. Н. Попантонопуло, В. П. Шувалов ; под ред. проф. В. П. Шувалова // Современные технологии. - 4-е изд., испр. и доп. - М. : Горячая линияТелеком, 2012. - Т.1. - 620 с.

5. Основные задачи и членство в ETSI [Электронный pecypc]. https://studbooks.net/2557824/tovarovedenie/evropeys kiy_institut_standartizatsii_oblasti_elektrosvyazi (дата звернення 10.11.2018).

6. Инфокоммуникационные системы и сети. Основы передачи и распределения информации в инфокоммуникационных системах и сетях [Текст]: учеб. пособие / И. А. Саитов, А. Е. Миронов, А. В. Королев, А. Н. Орешин; под ред. И. А. Саитова. - Орел : Академия ФСО России, 2016. - Ч. 1. - 281 с.

7. Гольдштейн, Б. С. Сети связи пост-NGN [Текст] / Б. С. Гольдштейн, А. Е. Кучерявый. - СПб. : БХВ-Петербург, 2013. - 160 с.

8. Співпраця 3 міжнародними організаціями. [Електронний ресурс]. -Режим доступу: http://www.ukrtelecom.ua/about/international/coopera tion (дата звернення 18.11.2018).

9. Новая цифровая платформа «Электронная библиотека МСЭ» [Электронный ресурс]. Режим доступа : http://www.itu.int/ (дата звернення 18.11.2018)

10. ITU-T Recommendation Y.2172. Service restoration priority levels in Next Generation Networks. 2007.

11. ITU-T Recommendation Y.2091. Terms and definitions for Next Generation Networks. 2007. 
12. Піневич, Т. О. Концептуальні підходи до організації транспортних мереж зв'язку Укрзалізниці [Текст] / Т. О. Піневич, А. Ю. Букін // Інформаційно-керуючі технології на залізничному транспорті. - 2018. - № 1. C. 17-23.

\section{Пиневич Т. А. Стандартизация инфокоммуни- кационных сетей и систем.}

Аннотация. В статье рассмотрены характеристики основных организаций по стандартизации и результаты их деятельности, связанные с разработкой рекомендаций, стандартов и других документов, регулирующих отрасль. Определено, что стандарты глобальной информационной инфраструктуры обеспечивают возможность взаимодействия и взаимосвязи между приложениями и различными платформами на основе программных и аппаратных средств. Отмечено, что без согласования всеми участниками телекоммуникационного рынка (операторами, производителями, поставщиками оборудования и пользователями) общепринятих стандартов для оборудования и протоколов, прогресс в деле построения инфокомуникационних сетей был бы невозможным. Отмечено, что в соответствии с международными декларациями, которые относятся к строительству информационного общества, перед Украиной, являющейся частью Глобальной информацийной инфраструктури, стоит важная задача - ускорить темпы развития и создания единой национальной мультисервисной широкополосной сети связи на базе европейских и международных стандартов.

Ключевые слова: Глобальная информационная инфраструктура, инфокоммуникации, стандарт, спецификация, протокол, стек протоколов, NGN, эталонная модель взаимодействия открытых систем.
Attention is drawn to the fact that the GII standards provide the opportunity for interaction and interconnection between a large variety of applications and platforms both on the basis of software and hardware, therefore, without the agreement of all participants in the telecommunications market (operators, manufacturers and suppliers of equipment, users) accepted standards for equipment and protocols, progress in the construction of infocommunication networks would be impossible.

According to international declarations, concerning the construction of an information society, Ukraine faces an important task to accelerate the pace of development and creation which based on European and international standards, on a single national multiservice broadband communications network, which is part of the Global Information Infrastructure.

Keywords: Global Information Infrastructure, Infocommunication, standard, specification, protocol, protocol stack, NGN, reference model of interaction of open systems.

Надійшла 16.11.2018 p.

Піневич Тетяна Олександрівна, стариий викладач кафедри «Телекомунікаційних технологій та автоматики» Державного університету інфраструктури та технологій, Київський інститут залізничного транспорту, Київ, Украӥна. E-mail: pinevichto@ukr.net ORCID: https://orcid.org/0000-00019046-2046

Tetiana Pinevych, Senior Lecturer, State University of Infrastructure and Technology, Kyiv Institute of Railway Transport, Department of Technology and Automation, Kyiv, Ukraine. E-mail: pinevichto@ukr.net ORCID: https://orcid.org/0000-0001-9046-2046

\footnotetext{
Pinevych Tetiana. Standardization of infocommunication networks and systems.

Abstract. In the Global Information Infrastructure (GII) compatibility problems of the national systems are very importaint. That is why normative and legal framework of the construction and operation of infocommunications should be carried out not only at the national level, but also at the international level.

A number of international organizations and forums such as ITU - International Telecommunication Union, ETSI European Telecommunication Standards Institute, ISO International Organization for Standardization, etc., are working on the solution of this problem, which develop standards and specifications in the field of infocommunications.
} 